\title{
Sources of Infection Among Confirmed Cases of COVID-19 in Jeju Province, Korea
}

\author{
Moonkyong Hwang ${ }^{1}$, Jong-Myon Bae ${ }^{1,2}$ \\ ${ }^{1}$ Jeju Center for Infectious Diseases Control and Prevention, Jeju, Korea, ${ }^{2}$ Department of Preventive Medicine, Jeju National University College of \\ Medicine, Jeju, Korea
}

Objectives: Jeju Province in Korea reported 627 coronavirus disease 2019 (COVID-19) cases between January 20, 2020, and March 31, 2021. This study analyzed the sources of infection among confirmed cases in Jeju Province, a self-governed island.

Methods: The sources of infection were broadly categorized as follows: (1) infections from overseas (confirmed patients who reported travel overseas or contact with overseas travelers); (2) infections from outside Jeju Province (confirmed patients who had visited other provinces or had contact with individuals who had traveled to other provinces in Korea); and (3) unknown sources of infection (confirmed patients who were infected following contact with an infected person whose source of infection was unknown). The chi-square test was used to analyze the differences in the distributions of related variables for each source of infection.

Results: Of the 627 confirmed cases, 38 (6.1\%) were infections from overseas sources, 199 (31.7\%) were from outside of Jeju Province, and 390 (62.2\%) were from unknown sources. Jeju Province had no cases with an unknown source of infection during the first and second waves of the nationwide outbreak.

Conclusions: Infections from overseas sources could be blocked from spreading to local communities in Jeju Province by conducting screening at the airport, along with the preemptive suspension of visa-free entry. In addition, considering the scale of the nationwide outbreak, measures must be established to delay outbreaks from unknown sources of infection caused by sources outside Jeju Province.

Key words: COVID-19, SARS-CoV-2, Outbreaks, Communicable disease control

\section{INTRODUCTION}

On February 11, 2020, the World Health Organization officially designated the disease that had been referred to as the "novel coronavirus" as coronavirus disease 2019 (COVID-19),

Received: May 24, 2021 Accepted: June 16, 2021

Corresponding author: Jong-Myon Bae

Department of Preventive Medicine, Jeju National University College of Medicine, 102 Jejudaehak-ro, Jeju 63243, Korea

E-mail: jmbae@jejunu.ac.kr

This is an Open Access article distributed under the terms of the Creative Commons Attribution Non-Commercial License (https://creativecommons.org/licenses/by$\mathrm{nc} / 4.0 /$ ) which permits unrestricted non-commercial use, distribution, and reproduction in any medium, provided the original work is properly cited. caused by severe acute respiratory syndrome coronavirus 2; since then, COVID-19 has become a pandemic posing a global threat to public health, with outbreaks continuing worldwide as of March 2021 [1]. In Korea, the first confirmed case was reported in a Chinese tourist who passed through immigration on January 20, 2020. The crisis alert level was subsequently raised to the highest level (level IV) on February 23, 2020 [2].

Jeju Province, which consists of islands located at a considerable distance from the Korean mainland and offers visa-free entry for overseas travelers, immediately suspended visa-free entry on January 27, 2020, because of the influx of COVID-19 cases from overseas. Since the nationwide level IV (highest) alert was issued on February 23, 2020 [2], Jeju's response was considered preemptive. However, despite this preemptive re- 
sponse, an unofficial report of the Jeju Provincial Office indicated that a Chinese resident of Wuhan had stayed in Jeju as a tourist without a visa from January 22 to January 25, 2020, and was confirmed to have COVID-19 on January 30, 2020, after returning home [3]. That report clearly illustrates the risk of the introduction of an infectious disease to Jeju Province following a pattern distinct from that affecting the rest of the country.

As of March 2021, more than 1 year has passed since the issuance of the level IV alert, with 3 outbreak waves occurring nationwide [4]. Jeju has had 627 confirmed cases to date. Thus, this study aimed to analyze the sources of infection of COVID-19 in Jeju Province. This study will serve as the basis for establishing Jeju's own quarantine strategy to prevent the influx of infectious diseases from overseas sources [5].

\section{METHODS}

This study included confirmed patients in Jeju Province who tested positive for COVID-19 by reverse transcription-polymerase chain reaction (RT-PCR). Accordingly, 627 cases confirmed between February 21, 2020, when the first confirmed case was reported in Jeju Province, and March 31, 2021, were selected from the database of the Integrated Management System for Diseases, an infectious disease-reporting system of the Korea Disease Control and Prevention Agency (http://is.kdca.go.kr). Information on the socio-demographic characteristics, including sex and age, and the clinical symptoms of confirmed patients was extracted from the database of COVID-19 reports of the Korea Disease Control and Prevention Agency and 627 in-depth epidemiology survey reports conducted by the six public health centers within Jeju Province. We also reviewed COVID-19 statistical data from the Infectious Disease Control Team of Jeju Province and broadly categorized the sources of infection into the following three categories, based on the latency period of the virus and the timing of contact: $(A)$ overseas: confirmed patients who traveled overseas or came into contact with individuals who had traveled overseas, (B) outside Jeju Province: confirmed patients who had visited other provinces in Korea or came into contact with those who did; and (C) unknown: confirmed patients with no identifiable source of infection in Jeju Province.

The chi-square test was used to analyze the differences in the distributions of the 3 sources of infection, with a statistical significance level of $5 \%$.

\section{Ethics Statement}

This study was approved by the Institutional Review Board of Jeju National University (2021-035).

\section{RESULTS}

\section{Distribution of Sources of Infection}

Of the 627 confirmed cases, 38 cases (6.1\%) were from overseas sources, 199 cases (31.7\%) were from other provinces in Korea, and 390 cases (62.2\%) were from unknown sources (Table 1). Among those with an overseas source of infection (traveled overseas or had contact with someone who had traveled overseas), most had a history of visiting foreign countries (37 cases, 5.9\%).

The cases with a source of infection from other provinces were

Table 1. Coronavirus disease 2019 cases by sources of infection

\begin{tabular}{|c|c|c|}
\hline Group & Source of infection & n $(\%)$ \\
\hline Total & & $627(100)$ \\
\hline \multicolumn{3}{|l|}{ Group A ( $n=38)$} \\
\hline \multirow{2}{*}{$\begin{array}{l}\text { Source from } \\
\text { overseas }\end{array}$} & a. Imported cases & $37(5.9)$ \\
\hline & b. Linked to imported cases (a) & $1(0.2)$ \\
\hline \multicolumn{3}{|l|}{ Group B ( $n=199)$} \\
\hline \multirow{9}{*}{$\begin{array}{l}\text { Source from } \\
\text { outside Jeju } \\
\text { province }\end{array}$} & $\begin{array}{l}\text { c. Visit/contact cases in other cities/ } \\
\text { provinces }\end{array}$ & $97(15.5)$ \\
\hline & $\begin{array}{l}\text { d. Major clusters of visit/contact cases in } \\
\text { other cities/provinces (c) }\end{array}$ & $52(8.3)$ \\
\hline & Seogwipo-si, S sauna & 7 \\
\hline & Jeju-si, Development Center & 5 \\
\hline & Jeju-si, guest house & 5 \\
\hline & Gyeongnam Jinju-si, group training & 14 \\
\hline & Jeju-si, mission group & 12 \\
\hline & Jeju-si, occupational rehabilitation center & 9 \\
\hline & $\begin{array}{l}\text { e. Linked to visit/contact cases in other } \\
\text { cities/provinces (c) }\end{array}$ & $50(8.0)$ \\
\hline \multicolumn{3}{|l|}{ Group C ( $n=390)$} \\
\hline \multirow{11}{*}{$\begin{array}{l}\text { Unknown } \\
\text { source of } \\
\text { infection }\end{array}$} & f. Major clusters in Jeju & $244(38.9)$ \\
\hline & Jeju-si, high school & 13 \\
\hline & Jeju-si East, religious facility & 33 \\
\hline & Jeju-si, academy & 8 \\
\hline & Jeju-si, H sauna & 86 \\
\hline & Jeju-si, live café & 61 \\
\hline & Jeju-si, welfare facility for disabled & 21 \\
\hline & Jeju-si, welfare facility for children & 15 \\
\hline & Jeju-si, restaurant & 7 \\
\hline & g. Under investigation & $47(7.5)$ \\
\hline & h. Linked to under investigation (g) & $99(15.8)$ \\
\hline
\end{tabular}




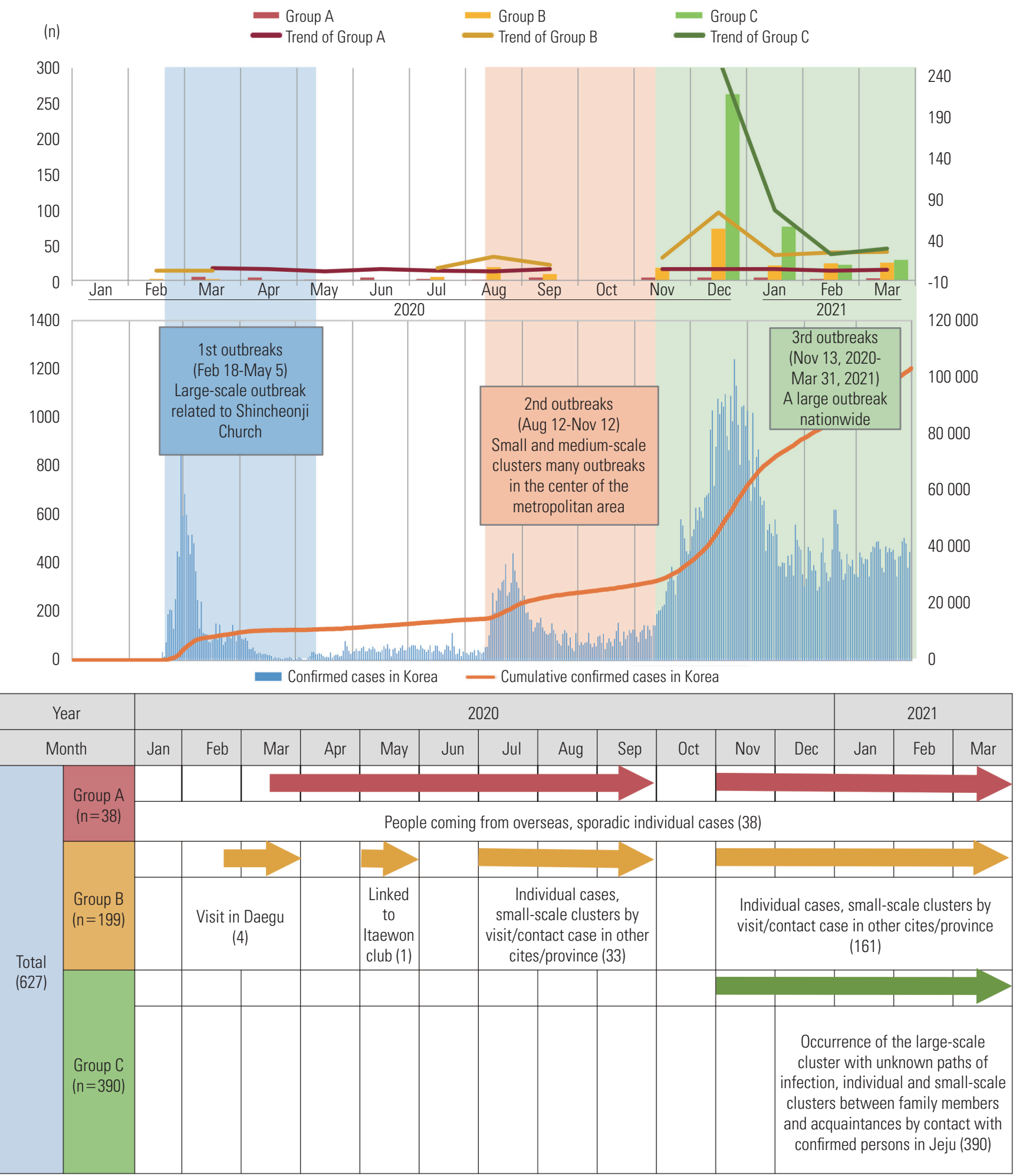

Figure 1. Trends of confirmed coronavirus disease 2019 cases in Jeju Province by month and year. Group A: confirmed patients who traveled overseas or came into contact with individuals who had traveled overseas; Group B: confirmed patients who had visited other provinces in Korea or came into contact with those who did; Group C: confirmed patients with no identifiable source of infection in Jeju Province. 
further divided into the following three categories: (1) infections among residents of Jeju Province who came into contact with infected people while visiting other provinces (97 cases, 15.5\%), (2) mass transmission of the disease by people who came to Jeju from other provinces and by residents of Jeju returning from visiting other provinces (52 cases, 8.3\%), and (3) transmission to residents of Jeju by imported cases (50 cases, $8.0 \%$ ).

The 244 cases (38.9\%) with an unknown source of infection belonged to a cluster of infections that occurred after the patients had used multipurpose facilities such as religious facilities, saunas, or live music cafes. These cases accounted for the highest percentage of all confirmed cases. There were 47 cases (7.5\%) for which the source of infection could not be detected and 99 confirmed cases (15.8\%) within the province who were infected through contact with cases with unknown sources of infection.

\section{Monthly Trends According to the Source of Infection}

Among cases with an overseas source of infection, the number of individual cases (e.g., as overseas visitors and international students) remained steady every month since March 2020, when the first case was reported, except for October 2020, when

Table 2. The number of confirmed coronavirus disease 2019 cases in Jeju Province by month and year

\begin{tabular}{llccr}
\hline Month & $\begin{array}{c}\text { Group A } \\
(\mathbf{n = 3 8 )}\end{array}$ & $\begin{array}{c}\text { Group B } \\
(\mathbf{n}=\mathbf{1 9 9})\end{array}$ & $\begin{array}{c}\text { Group C } \\
(\mathbf{n = 3 9 0 )}\end{array}$ & $\begin{array}{c}\text { Total } \\
(\mathbf{n}=\mathbf{6 2 7})\end{array}$ \\
\hline Feb 20 & $0(0.0)$ & $2(1.0)$ & $0(0.0)$ & $2(0.3)$ \\
Mar 20 & $5(13.2)$ & $2(1.0)$ & $0(0.0)$ & $7(1.1)$ \\
Apr 20 & $4(10.5)$ & $0(0.0)$ & $0(0.0)$ & $4(0.6)$ \\
May 20 & $1(2.6)$ & $1(0.5)$ & $0(0.0)$ & $2(0.3)$ \\
Jun 20 & $4(10.5)$ & $0(0.0)$ & $0(0.0)$ & $4(0.6)$ \\
Jul 20 & $2(5.3)$ & $5(2.5)$ & $0(0.0)$ & $7(1.1)$ \\
Aug 20 & $1(2.6)$ & $19(9.5)$ & $0(0.0)$ & $20(3.2)$ \\
Sep 20 & $4(10.5)$ & $9(4.5)$ & $0(0.0)$ & $13(2.1)$ \\
Oct 20 & $0(0.0)$ & $0(0.0)$ & $0(0.0)$ & $0(0.0)$ \\
Nov 20 & $4(10.5)$ & $18(9.0)$ & $0(0.0)$ & $22(3.5)$ \\
Dec 20 & $4(10.5)$ & $73(36.7)$ & $263(67.4)$ & $340(54.2)$ \\
Jan 21 & $4(10.5)$ & $21(10.6)$ & $76(19.5)$ & $101(16.1)$ \\
Feb 21 & $2(5.3)$ & $24(12.1)$ & $22(5.6)$ & $48(7.7)$ \\
Mar 21 & $3(7.9)$ & $25(12.6)$ & $29(7.4)$ & $57(9.1)$ \\
\hline
\end{tabular}

Values are presented as number (\%).

Group A: confirmed patients who traveled overseas or came into contact with individuals who had traveled overseas; Group B: confirmed patients who had visited other provinces in Korea or came into contact with those who did; Group C: confirmed patients with no identifiable source of infection in Jeju Province. there was no case with an overseas source of infection (Figure 1).

Among cases with a source of infection from outside Jeju Province, four confirmed cases had visited Daegu during the first wave of the nationwide outbreak (February 18, 2020 to May 5, 2020), during which there was a large-scale outbreak centered around a specific church in Daegu [6]. During the second wave of the outbreak (August 12, 2020 to November 12, 2020), 33 individual and small-group cases were reported among those who had visited other provinces and those who had been in contact with confirmed cases in other provinces between July and September. No confirmed cases were reported in October 2020; however, several sporadic small-scale outbreaks have occurred since November, when the third wave of the nationwide outbreak began (November 13, 2020 to March 31, 2021) (Table 2).

Among cases with an unknown source of infection, there was a large-scale outbreak in December 2020 during the third wave of the nationwide outbreak, with sporadic small-scale outbreaks continuing to occur between January and March 2021.

\section{Comparisons of Demographic and Clinical Characteristics According to the Source of Infection}

Among the 627 confirmed cases, 327 (52.2\%) were female; however, there were no sex differences among the three

Table 3. Summary of epidemiologic characteristics of coronavirus disease 2019 in Jeju Province, Korea

\begin{tabular}{lccccc}
\hline $\begin{array}{l}\text { Characteris- } \\
\text { tics }\end{array}$ & $\begin{array}{c}\text { Group A } \\
(\mathbf{n = 3 8})\end{array}$ & $\begin{array}{c}\text { Group B } \\
(\mathbf{n}=\mathbf{1 9 9})\end{array}$ & $\begin{array}{c}\text { Group C } \\
(\mathbf{n}=\mathbf{3 9 0})\end{array}$ & $\begin{array}{c}\text { Total } \\
(\mathbf{n}=\mathbf{6 2 7})\end{array}$ & $\boldsymbol{p}$-value \\
\hline Sex & & & & & \\
$\quad$ Male & $18(47.4)$ & $93(46.7)$ & $189(48.5)$ & $300(47.8)$ & 0.920 \\
Female & $20(52.6)$ & $106(53.3)$ & $201(51.5)$ & $327(52.2)$ & \\
Age (y) & & & & & \\
$0-19$ & $1(2.6)$ & $21(10.6)$ & $72(18.5)$ & $94(15.0)$ & $<0.001$ \\
$20-39$ & $26(68.4)$ & $69(34.7)$ & $80(20.5)$ & $175(27.9)$ & \\
$40-59$ & $8(21.1)$ & $80(40.2)$ & $145(37.2)$ & $233(37.2)$ & \\
$\geq 60$ & $3(7.9)$ & $29(14.6)$ & $93(23.8)$ & $125(19.9)$ & \\
Clinical & & & & & \\
Symptomatic & $8(21.1)$ & $136(68.3)$ & $251(64.4)$ & $395(63.0)$ & $<0.001$ \\
Asymptomatic & $30(78.9)$ & $63(31.7)$ & $139(35.6)$ & $232(37.0)$ & \\
\hline
\end{tabular}

Values are presented as number (\%).

Group A: confirmed patients who traveled overseas or came into contact with individuals who had traveled overseas; Group B: confirmed patients who had visited other provinces in Korea or came into contact with those who did; Group C: confirmed patients with no identifiable source of infection in Jeju Province.

${ }^{1}$ Chi-square test. 
groups defined by the source of infection ( $p=0.92$ ) (Table 3 ). Nevertheless, there were differences according to age $(p<0.001)$. The highest frequency of cases with an overseas source of infection was observed in the 20-year to 39-year age group, whereas in cases with an unknown source of infection, the highest frequency was observed in the 40-year to 59-year group. Over half of patients $(n=395,63.0 \%)$ complained of symptoms that could be indicative of COVID-19. However, only 8 patients (21.1\%) among those with an overseas source of infection showed symptoms, reflecting a significant difference compared to cases with infection sources from other provinces and unknown sources $(p<0.001)$. The distribution of symptoms is summarized in Supplemental Material 1.

\section{DISCUSSION}

Most confirmed COVID-19 cases in Jeju Province had an unknown source of infection, followed by out-of-province and overseas sources of infection. However, each of the three waves of the nationwide outbreak had a different distribution. During the first wave, no cases had an unknown source of infection, while a small number of individual cases were caused by overseas and out-of-province sources. During the second wave in August 2020, cases with an out-of-province source peaked at 19 , while those with an unknown source of infection remained at 0 . However, when the third wave started in December 2020, 263 confirmed cases had an unknown source of infection following the occurrence of large-scale cluster infections. This could be attributed to the rapid spread of the disease from high-risk multipurpose facilities in closed spaces such as saunas, indoor sports facilities, and bars.

Notably, there were no cases with an unknown source of infection until November 2020, but there was a surge in such cases in December 2020, compared to 19 and 18 cases with out-of-province sources of infection in August and November 2020, respectively. The peak in December 2020 may be attributed to out-of-province sources of infection. The reason for this is that the nationwide proportion of unknown sources in the first, second, and third waves was $9.3 \%, 14.9 \%$, and $22.6 \%$, respectively, showing an increasing trend [4]. However, this proposed explanation is difficult to verify, as many COVID-19 cases remain asymptomatic and may not be reported [5-7]; thus, the source of infection can only be confirmed through verbal reports. The 47 confirmed cases (7.5\%) with unknown sources of infection (Table 1) could have resulted from failure of quarantine measures in the local community. Similarly, the occurrence of these cases during the third wave may illustrate the difficulty of preventing the influx of infections into Jeju Province unless the movement of people and goods between provinces is blocked during prolonged COVID-19 outbreaks.

In contrast, all cases with an overseas source of infection were individual cases and did not lead to clusters of infections or spread to local communities despite a relatively high proportion of asymptomatic cases (Table 3), likely due to awareness of the risk of introducing infection from overseas [8]. Hence, Jeju Province issued the highest level of crisis alert early in the pandemic and suspended visa-free entry while implementing a fever monitoring system at the airport and walk-through testing at departure to prevent overseas cases from entering the province. Thus, such preemptive measures would be effective in preventing the entry of infection from overseas sources in Jeju Province.

The age distribution of COVID-19 cases differed according to the source of infection. Among patients with an overseas source of infection, the 20-year to 39-year group accounted for more than half of the total cases, as people in this age group frequently travel overseas for education and employment. In contrast, the 40-year to 59-year group, which is the most active in terms of socioeconomic activity, accounted for most of the out-ofprovince and unknown sources of infection, followed by the 20-year to 39-year group. These findings suggest a high-risk of infection in those with high-levels of social contact due to socioeconomic activities; these groups then transmit the virus to family members, including teenagers or elderly adults aged over 60 years.

The major limitation of this study is that the verification of the source of infection relied entirely on verbal reports of confirmed cases through an epidemiological survey. Thus, our results may have been affected by uncertainty in memory recall, unintended inaccurate reports, or unconscious dishonesty, all of which could have contributed to inaccuracy in recalling the timing of infection. Despite these limitations, the timing of infection was inferred for individual cases based on the onset of clinical symptoms, testing dates, and RT-PCR cycle threshold values and verified with associated objective information such as the history of credit card usage and places visited.

An analysis of confirmed COVID-19 cases in Jeju Province showed three major sources of infection. Regarding overseas sources of infection, the spread of the disease to local communities could be prevented by the preemptive suspension of vi- 
sa-free entry and screening at the airport. However, with an increase in the scale of the nationwide outbreak, out-of-province infections increased, resulting in a group of patients with unknown sources of infection, indicating COVID-19 spread in the local communities. The tourism industry accounts for a large proportion of economic activity in Jeju Province, meaning that there is a higher risk of infectious diseases due to influx from abroad than in other provinces [9]. Therefore, Jeju Province must establish measures to prevent the introduction of out-of-province infections to delay transmission through unknown sources. In particular, personal protective equipment and social distancing should be emphasized for residents of Jeju Province to prevent infections transmitted by residents of Jeju Province who encounter undiagnosed cases while visiting other provinces [2]. Additionally, an understanding of the situation and active cooperation by residents are necessary for the implementation of preventive strategies, in addition to establishing a system that provides rapid and accessible testing.

\section{SUPPLEMENTAL MATERIALS}

Supplemental material is available at https://doi.org/10. 3961/jpmph.21.286.

\section{CONFLICT OF INTEREST}

The authors have no conflicts of interest associated with the material presented in this paper.

\section{FUNDING}

None.

\section{ACKNOWLEDGEMENTS}

We are grateful to the staff in charge of infectious diseases at the six public health centers in Jeju Province for performing the epidemiological survey of confirmed COVID-19 cases, and the Infectious Disease Control Team at the Jeju Provincial Office for interpreting the sources of infection by analyzing the epidemiological reports.

\section{AUTHOR CONTRIBUTIONS}

Conceptualization: MH, JMB. Data curation: MH. Formal analysis: MH, JMB. Funding acquisition: None. Methodology: JMB. Project administration: JMB. Visualization: MH. Writing original draft: $\mathrm{MH}$. Writing - review \& editing: $\mathrm{MH}, \mathrm{JMB}$.

\section{ORCID}

Moonkyong Hwang https://orcid.org/0000-0003-4200-5910 Jong-Myon Bae https://orcid.org/0000-0003-3080-7852

\section{REFERENCES}

1. Hong KH, Lee SW, Kim TS, Huh HJ, Lee J, Kim SY, et al. Guidelines for laboratory diagnosis of coronavirus disease 2019 (COVID-19) in Korea. Ann Lab Med 2020;40(5):351-360.

2. Kang J, Jang YY, Kim J, Han SH, Lee KR, Kim M, et al. South Korea's responses to stop the COVID-19 pandemic. Am J Infect Control 2020;48(9):1080-1086.

3. Bae JM. A Chinese case of COVID-19 did not show infectivity during the incubation period: based on an epidemiological survey. J Prev Med Public Health 2020;53(2):67-69.

4. Kim Y, Kim YY, Yeom H, Jang J, Hwang I, Park K, et al. COVID-19 1-year outbreak report as of January 19, 2021 in the Republic of Korea. Public Health Wkly Rep 2021;14(9):472-481 (Korean).

5. Song SW, Kim D, Park JY, Lee S. Symptoms and characteristics which require attention during COVID-19 screening at a port of entry. J Korean Med Sci 2021;36(2):e14.

6. Kim SW, Kim SM, Kim YK, Kim JY, Lee YM, Kim BO, et al. Clinical characteristics and outcomes of COVID-19 cohort patients in Daegu metropolitan city outbreak in 2020. J Korean Med Sci 2021;36(1):e12.

7. Kim GU, Kim MJ, Ra SH, Lee J, Bae S, Jung J, et al. Clinical characteristics of asymptomatic and symptomatic patients with mild COVID-19. Clin Microbiol Infect 2020;26(7):948.e1-948.e3.

8. Craig AT, Heywood AE, Hall J. Risk of COVID-19 importation to the Pacific islands through global air travel. Epidemiol Infect 2020;148:e71.

9. Bae JM. Surveillance operation for the 141st confirmed case of Middle East respiratory syndrome coronavirus in response to the patient's prior travel to Jeju Island. Epidemiol Health 2015;37:e2015035. 